\title{
Spatiotemporal Distribution and Trend Analysis of Waterborne Diseases in Kalahandi District of Odisha, India
}

\author{
Martand Mani Mishra, Netrananda Sahu
}

Department of Geography, Delhi School of Economics, University of Delhi, Delhi, India. DOI: https://doi.org/10.24321/0019.5138.202170

I $\mathbf{N} \quad \mathbf{F} \mathbf{O}$

\section{Corresponding Author:}

Netrananda Sahu, Department of Geography, Delhi School of Economics, University of Delhi, Delhi, India.

E-mail Id:

babunsahu@gmail.com

Orcid Id:

https://orcid.org/0000-0001-8505-7185

How to cite this article:

Mishra MM, Sahu N. Spatiotemporal Distribution and Trend Analysis of Waterborne Diseases in Kalahandi District of Odisha, India. J Commun Dis. 2021;53(4):23-28.

Date of Submission: 2021-09-03

Date of Acceptance: 2021-12-07

\section{$\begin{array}{llllllll}\mathbf{A} & \mathbf{B} & \mathbf{S} & \mathbf{T} & \mathbf{R} & \mathbf{A} & \mathbf{C} & \mathbf{T}\end{array}$}

Background: For several decades, the Kalahandi district of Odisha, India has been designated as a place of poverty, disease, starvation and death. The occurrence and resurgence of water-borne diseases in Kalahandi is a major cause of morbidity and mortality in the district.

Material and Method: Data on incidences of Acute Diarrhoeal Disease (ADD) and typhoid were collected from the District Health Office, Kalahandi, Odisha, for the annual incidence from 2015 to 2018. The study uses descriptive epidemiological method to analyse the spatiotemporal trend of two major waterborne diseases, ADD and typhoid that are predominantly found in the blocks of the district. The growth rate of these diseases has also been calculated to examine the growth of cases in each block.

Result: We have found that the distribution of both diseases is highly uneven at the block level. Diarrhoea is found to be prevalent in all the blocks whereas typhoid is concentrated in a few blocks only. Spatially we found that the blocks lying in the central zone of the district are the hotspots for diarrhoea. Typhoid is highly dominant in the district headquarter Bhawanipatna and northern block Madanpur Rampur. The result also reveals that the cases of diarrhoea are declining and typhoid is increasing in the blocks.

Conclusion: There are several underlying causes for the uneven distribution of these diseases, like undernutrition of children, contamination of water, overexploitation of groundwater, low percentages of villages covered with rural drinking water, and poor health infrastructure prevailing in the district.

Keywords: Spatiotemporal Distribution, Diarrhoea, Typhoid, Kalahandi, Odisha

\section{Introduction}

Water is the most important resource on the planet Earth but the availability of clean and hygienic water is in scant quantity. ${ }^{1}$ The quality of available drinking water has an immense impact on the health status of people. Waterborne diseases are caused by pathogens, and contaminations ${ }^{2}$ 
have always been a cause of concern in a country like India which is facing several challenges like the nonavailability of clean drinking wate, proper sanitation sewage management, and above all poor health infrastructure. Water gets contaminated due to several anthropogenic activities which include the use of fertilisers and pesticides, chemical exposure due to industrial waste, and household chemical waste..$^{3-5}$ Major waterborne diseases found in different parts of the country are typhoid, diarrhoea, jaundice, and cholera. ${ }^{6}$ The three main factors that influence the pattern of these diseases, their geographical stretch, and their impact on the population are meteorological, social, and demographic characteristics. ${ }^{7}$ The metrological factors include rainfall, temperature, humidity, and the number of rainy days ${ }^{8-11}$ whereas socio-demographic factors include composition of the population, distribution of the population, their economic capacity, and available health system. ${ }^{12}$

Waterborne diseases like acute diarrhoeal disease (ADD) and typhoid are one of the major causes of morbidity and mortality in developing countries like India. Out of the total deaths recorded related to diarrhoea, over $90 \%$ of them are of infants below the age of five. ${ }^{5}$ The ramification of waterborne diseases accelerates in the socio-economically backward areas due to a high level of sensitivity and a low level of adaptive capacity. In the present work, the study area "Kalahandi district" lies in the south-western part of Odisha in India and, is better known for the prevalence of hunger, poverty, death, and diseases. This research article aims to analyse the spatial distribution, trend, and pattern of two major water-borne diseases prevalent in the various blocks of the district. This study is a micro-level analysis to identify the hotspots of ADD and typhoid in the district. Due to low level of education, poor economic condition, and localised sources of drinking water, there are higher incidences of both diseases in the district. The district literacy rate is $59.22 \%$ which is far below the state literacy rate $(72.9 \%)$. In the state of Odisha, this district is considered one of the most backward districts and has received backward funds from the government. ${ }^{13}$ Though the history of diseases and related deaths are wellestablished facts of the district still, it is very difficult to find literature that examines the diseases at the micro-level. We have examined the two most prevalent waterborne diseases (ADD and typhoid) in the blocks of the district and explored their spatiotemporal distribution. In the second part, we aim to understand the year-to-year and average growth of cases separately for both the diseases between the years 2015 and 2018.

\section{Materials and Method}

\section{Study Area}

Kalahandi district is located between $19.30^{\circ} \mathrm{N}$ and $21.50^{\circ}$
$\mathrm{N}$ latitudes and $82.20^{\circ} \mathrm{E}$ and $83.47^{\circ} \mathrm{E}$ longitudes in the eastern state of Odisha, India ${ }^{14}$ (Figure 1(a)). The district shares nearly five per cent of the total state area and has nearly $3.76 \%$ of the state population. The population in the district is dominated by the schedule tribe (28.5\%) and the scheduled caste population. This district is one of the most socially and economically backward districts in the country. The district has been divided into two major sub-divisions i.e., Bhawanipatna, and Dharmagarh. Further, these two sub-blocks are divided into seven and six blocks respectively.

\section{Data Collection}

This study is purely based on the secondary source of data. Data for the two dominant waterborne diseases for each block of the district were collected from the district health office for the annual incidence from 2015 to 2018. In the district, data on diseases is maintained by Integrated Disease Surveillance Program (IDSP).

\section{Statistical Analysis}

The yearly percentage increase in incidence has been calculated for each block by applying the below formula:

Yearly Percentage Increase in Incidence $=\frac{\mathrm{I}-\overline{\mathrm{A}}}{\overline{\mathrm{A}}} * 100$

Here, $\mathrm{I}=$ incidence in a particular year, $\bar{A}=$ incidence in the previous year.

Further, for calculation of the average growth of cases between 2015 and 2018, we have calculated the mean incidence in each block. Later we have applied similar formula used in equation (1) and have replaced the value of $\bar{A}$ from the incidence in the previous year to the average incidence from 2015 to 2018 for each block. The percentage growth rate has been computed through Microsoft Excel 2019 and SPSS 22.0. The maps in the manuscript have been generated through ArcGIS version 10.2, a mapping and analysis tool.

\section{Result}

The proportional distribution of the diseases was found to be very uneven among the blocks of the district. Geographically, the distribution of both the water-borne diseases in the district revealed that ADD was present in all the blocks of the district whereas typhoid was nearly absent from the Golamunda block in the western zone, Junagarh in the central zone, Jaipatna and Thuamal Rampur in the southern zone from 2015 to 2018. At the block level, the incidences of ADD are more dominant than typhoid. We found through the proportional distribution of cases that typhoid is found spatially focused in three northern blocks (Narla, Kalamunda, and Madanpur Rampur) and one central block (Bhawanipatna). In comparison to typhoid, ADD was found to have a higher impact in the southern blocks (Junagarh, Kalampur, Jaipatna, and Kokasara), western 
blocks (Golamunda and Dharmagarh), and in the eastern blocks (Lanjigarh and Thuamal Rampur). The cases of typhoid and ADD were found nearly equal in the Narla block of the district (Figure 1(b)).

The cases of ADD were dominant in the central zone of the district. High incidences of ADD were reported from Bhawanipatna, Junagarh, Kesinga, Golamunda, and Madanpur Rampur. Bhawanipatna and Junagarh blocks of the district had the highest incidence which was about two times higher than the district average and ten times more than the Narla and Dharmagarh block. The southern blocks (Kokasara, Kalampur, Thuamal Rampur, and Jaipatna) of the district had recorded a low incidence of ADD. Lanjigarh and Karlamunda blocks lying in the eastern and northern regions respectively have incidences equivalent to the district average (Figure $1(\mathrm{c})$ ). Cases of typhoid were exceptionally high in the Bhawanipatna and Madanpur block of the district. Junagarh, Jaipatna and Thuamal Rampur block had recorded the lowest number of incidences of typhoid in the district (Figure 1(d)).

In the next phase of the study, we calculated the yearly and average growth of cases in each block during the period between 2015 and 2018. In the yearly analysis, we found that the cases of ADD had shown a decreasing trend in almost all the blocks except Bhawanipatna where it had shown an increasing trend in the years 2016 and 2018. In the year 2016, maximum blocks (09) had shown an increasing trend whereas it had decreased to 05 in 2017 and only 02 in 2018 (Figure 2a). An opposite trend had been observed in the case of typhoid in the blocks. Seven blocks out of thirteen had seen a positive growth during the year 2016. The positive growth in the cases from 2016 to 2017 had a sharp rise in six blocks i.e., Madanpur Rampur, Lanjigarh, Golamunda, Kalampur, Kokasara, and Junagarh blocks. The cases had shown a very low percentage of negative change in almost all the blocks except Lanjigarh and Golamunda (Figure 2b). Interestingly, we found that in Lanjigarh block of the district, ADD had decreased in all the years whereas the cases of typhoid had a high positive growth (Figures $2 a$ and $2 b)$.

Later in the last phase of the study, the average growth of cases was calculated from 2015 to 2018 for ADD and typhoid (Figures $2 \mathrm{c}$ and $2 \mathrm{~d}$ ). It was found that the incidence of ADD had shown a continuous increase from 2015 to 2017 in the majority of blocks. During the years 2015, 2016, and 2017, 07,11 , and 09 blocks had shown an average positive growth in cases. Karlamunda block lying in the northern region of the district had shown consecutive average positive growth in the years 2016, 2017, and 2018 (Figure 2c).

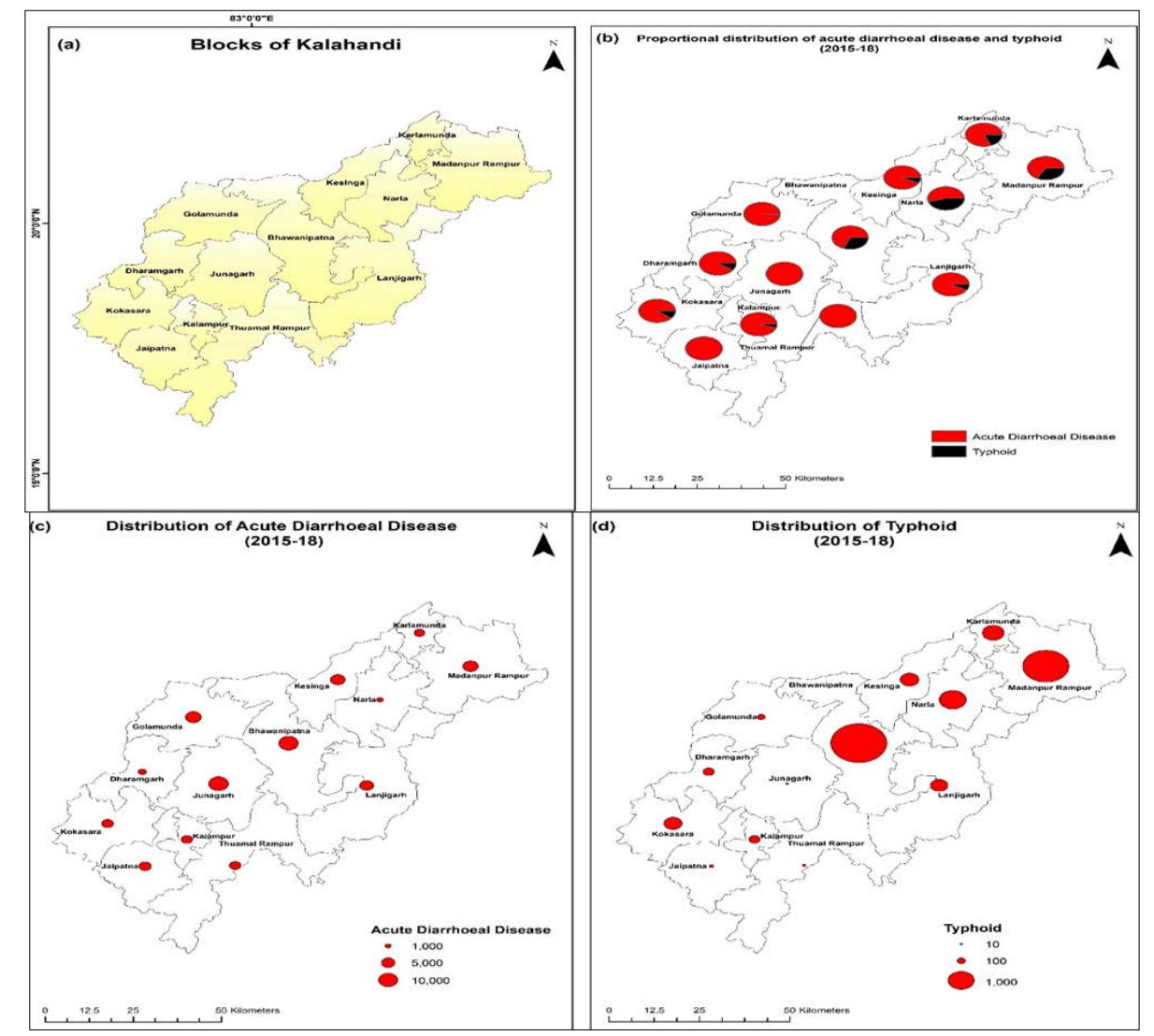

Figure I.(a)The Study Area (b) Proportional Distribution of ADD and Typhoid (c) Distribution of ADD Cases (d) Distribution of Typhoid Cases in the Blocks of the Kalahandi District between 2015 and 2018 


\begin{tabular}{|c|c|c|c|c|c|c|c|c|c|c|}
\hline \multicolumn{5}{|c|}{ (a) Annual growth rate of ADD } & \multicolumn{6}{|c|}{ (b) Annual growth rate of typhoid } \\
\hline \multirow[t]{2}{*}{ Blocks } & \multicolumn{4}{|c|}{ Years } & Blocks & \multicolumn{5}{|c|}{ Years } \\
\hline & 2016 & 2017 & \multicolumn{2}{|c|}{2018} & & \multicolumn{2}{|l|}{2016} & 2017 & \multicolumn{2}{|c|}{2018} \\
\hline Madanpur Rampur & \multicolumn{4}{|c|}{$=$} & Madanpur Rampur & & $=$ & 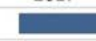 & \\
\hline Narla & \multicolumn{4}{|c|}{$=$} & Narla & $\overline{2}$ & & & \\
\hline Karlamunda & \multicolumn{4}{|c|}{$\bar{\square} \bar{\square}$} & Karlamunda & & & & & \\
\hline Kesinga & \multicolumn{4}{|l|}{ a } & Kesinga & & & & & \\
\hline Lanjigarh & \multicolumn{4}{|l|}{$\overline{=}$} & Lanjigarh & & & & & \\
\hline Bhawanipatna & \multicolumn{4}{|c|}{$=$} & Bhawanipatna & & & & & \\
\hline Tauamul Rampur & \multicolumn{4}{|c|}{$=$} & Tauamul Rampur & & & & & \\
\hline Golamunda & \multicolumn{4}{|c|}{$=\square$} & Golamunda & & & & & \\
\hline Kalampur & \multicolumn{4}{|c|}{$\square \bar{\square}$} & Kalampur & & & & & \\
\hline Kokasara & \multicolumn{4}{|l|}{$\longrightarrow$} & Kokasara & & & & & \\
\hline Dharamgarh & \multicolumn{4}{|l|}{-} & Dharamgarh & & & & & \\
\hline Jayapatna & \multirow[t]{2}{*}{ 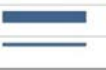 } & & - & & Jayapatna & & & & & \\
\hline Junagarh & & & & & Junagarh & & & & & \\
\hline \multicolumn{5}{|c|}{$\begin{array}{l}\text { (c) Annual average growth rate of ADD } \\
(2015-18)\end{array}$} & \multicolumn{6}{|c|}{$\begin{array}{l}\text { (d) Annual average growth rate of typhoid } \\
(2015-18)\end{array}$} \\
\hline \multirow[t]{2}{*}{ Blocks } & & Yea & & & Blocks & & & Yea & ars & \\
\hline & 2015 & 2016 & 2017 & 2018 & & & 2015 & 2016 & 2017 & 2018 \\
\hline Madanpur Rampur & - & $=$ & - & 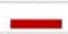 & Madanpur Rampur & & 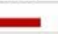 & 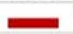 & $=$ & $=$ \\
\hline Narla & 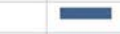 & $\longrightarrow$ & - & 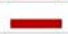 & Narla & & & & 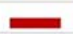 & 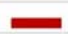 \\
\hline Karlamunda & 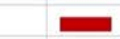 & & & & Karlamunda & & 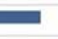 & - & 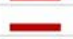 & 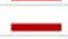 \\
\hline Kesinga & 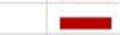 & ב & - & - & Kesinga & & 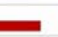 & $=$ & & - \\
\hline Lanjigarh & $\square$ & - & $\longrightarrow$ & 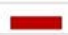 & Lanjigarh & & 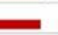 & - & $\longrightarrow$ & = \\
\hline Bhawanipatna & - & $\square$ & 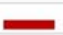 & - & Bhawanipatna & & - & $=$ & - & \\
\hline Tauamul Rampur & - & $=$ & $\bar{Z}$ & 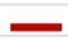 & Tauamul Rampur & & 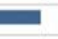 & - & $\longrightarrow$ & \\
\hline Golamunda & 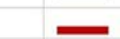 & - & $\bar{\square}$ & 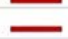 & Golamunda & & 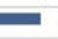 & 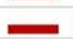 & $\square$ & $=$ \\
\hline Kalampur & 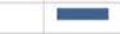 & - & - & 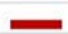 & Kalampur & & 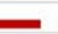 & ב & 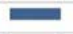 & - \\
\hline Kokasara & - & - & $=$ & 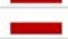 & Kokasara & & E & $\bar{\square}$ & $=$ & - \\
\hline Dharamgarh & 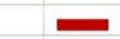 & - & E & $\bar{\square}$ & Dharamgarh & & $\bar{E}$ & - & $\longrightarrow$ & 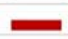 \\
\hline Jayapatna & - & $=$ & - & 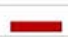 & Jayapatna & & - & $=$ & $\longrightarrow$ & $\longrightarrow$ \\
\hline Junagarh & $\longrightarrow$ & $\longrightarrow$ & $=$ & 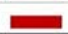 & Junagarh & & - & 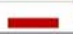 & 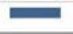 & - \\
\hline
\end{tabular}

Figure 2.(a) and (b).Calculated Value of the Annual Growth Rate of ADD and Typhoid Cases for 2016, 2017, and 2018. (c) and (d). Annual Average Growth Rate of ADD and Typhoid for 2015, 2016, 2017, and 2018. The Red and Blue Colours in the Figure Represent Negative and Positive Growth Respectively

Except for the Karlamunda block, all other blocks had shown a declining pattern in 2018 . In comparison to ADD, we found that the average positive growth rate of typhoid is less in the number of blocks, i.e., in 2015 (06), 2016 (06), and 2017 (04). We found that in 2018, the positive growth of typhoid was dominant in more blocks in comparison to ADD (Figure 2d).

\section{Discussion}

Numerous scholarly works have suggested that diarrhoea is the biggest threat for children under the age of five, as they are the most sensitive to this disease. ${ }^{15-18}$ Their sensitivity and vulnerability increase more in the sociobackward districts like Kalahandi which is mentioned as a symbol of poverty, diseases, starvation, and death, and is facing many other challenges like issues of educational backwardness, the problem of health care capacity in its blocks, non-availability of doctors and people's belief on uneducated doctors. ${ }^{19}$ The cases of ADD are nearly stable in the district but typhoid has shown a rise and it is showing an increasing trend at the district level. In a recently published scholarly work on Kalahandi, it has been mentioned that there is extreme variation in the rainfall among the blocks of the district. ${ }^{19}$ Increase in rainfall in a particular region increases the probability of waterborne diseases. ${ }^{20}$ Though in Kalahandi, the Thuamal Rampur block received maximum annual average rainfall, ${ }^{19}$ yet we observed that the cases related to diseases were very low in the block. The combination of demographical, sociological, and infrastructural factors have been observed to be more dominant in the district than the climatic factor.

Bhawanipatna, the district headquarter is the most urbanised block of the district that has seen a higher incidence for both diseases. Urbanisation, higher population density, overextraction of ground water, and contamination of water due to improper water disposal may be the causes for urbanised blocks like Bhawanipatna, Kesinga, and Junagarh to record a higher incidence in the district. Several factors like a higher percentage of the marginalised population (SC and ST), percentage of children below the age of six, percentage of population below poverty line, and low percentage of villages with rural drinking water supply are the prominent reasons for putting the blocks like Lanjigarh, Madanpur Rampur, Golamunda, Karlamunda, and Kokasara ${ }^{19}$ into the medium category of incidences recorded for ADD and typhoid. Dharmagarh block of the district having the lowest percentage of marginalised population and nearly $85 \%$ of the villages having rural drinking water system may be significant causes for the very low incidence in these blocks. Thuamal Rampur block of the district is the least exposed among all the blocks. It is really interesting that on all the socio-economic indicators Thuamal Rampur is highly 
negative still the cases in the block are nearly negligible. The natural environment of the district is also very different from others as it lies in the Eastern Ghats. There is a high chance that either the immunity and natural strength of the population is an important cause for less incidence or the cases are not being recorded because education and poverty in the block are the lowest and highest respectively among all the blocks.

\section{Conclusion}

The study is a significant step that tries to find out the hotspot of two major diseases and their trend and pattern in one of the most socio-economically backward districts of the country. This work has been done after going through all the possible available secondary sources of data and fieldwork which help in understanding the ground reality and causes of incidence in a particular block. It is highly helpful in understanding which blocks are highly sensitive to these diseases. In the Kalahandi district, ADD and typhoid incidences are found in both the urbanised and non-urbanised areas. The nutrition of children is also an important factor in deciding diseases like ADD as it is mostly them who suffer from this disease. Decreasing undernutrition of the children in highly exposed districts will be very helpful in reducing the incidence. Improving the nutrition level of children under the age of five will help in decreasing the cases of ADD in the district. Education is the best tool to remove all the social ills and therefore it is necessary to educate the local population of the district. Improvement in the healthcare facilities is also required in all the blocks of the district. There is a need for proper disease data maintenance in the district so that more studies can be done.

\section{Limitation of the Study}

The limitation of the study is that we wanted to do a longterm trend and seasonal analysis but we could not do so due to non-availability of data. If monthly data were available, we could have tried to find out the most sensitive months for each block.

\section{Author's Contribution}

MMM and NS conceptualised the central idea. MMM carried out the analysis, wrote the article, and drew all the figures. NS supervised the work. NS edited and commented on the manuscript. The authors have read and agreed to the publication.

\section{Acknowledgement}

We are grateful to the support provided by the Kalahandi district health department officials for proving data on incidences. We are thankful to the Department of Geography, Delhi School of Economics, the University of Delhi for providing access to ArcGIS Version 10.2 that was used to draw the map, MS Excel 2019, and SPSS version 22.0 that was used to do the calculation.

\section{Financial Support and Sponsorship: None Conflict of Interest: None \\ References}

1. Cabral JPS. Water microbiology. Bacterial pathogens and water. Int J Environ Res Public Heal. 2010 Oct;7(10):3657-703. [PubMed] [Google Scholar]

2. Subramanian VS, Cho MJ, Tan SZ, Fayzieva D, Sebaly C. Spatial distribution and trends of waterborne diseases in Tashkent Province. Cent Asian J Glob Heal. 2017 Jul;6(1):277. [PubMed] [Google Scholar]

3. Ashbolt NJ. Microbial contamination of drinking water and disease outcomes in developing regions. Toxicology. 2004 May;198(1-3):229-38. [PubMed] [Google Scholar]

4. Sharma S, Bhattacharya A. Drinking water contamination and treatment techniques. Appl Water Sci. 2016;7(3):1043-67. [Google Scholar]

5. Ali SA, Ahmad A. Analysing water-borne diseases susceptibility in Kolkata Municipal Corporation using WQI and GIS-based Kriging interpolation. Geo J. 2019;85(4):1151-74. [Google Scholar]

6. Karande K, Tandon S, Vijay R, Khanna S, Banerji T, Sontakke Y. Prevalence of water-borne diseases in western India: dependency on the quality of potable water and personal hygiene practices. J Water Sanit Hyg Dev. 2021;11(3):405-15. [Google Scholar]

7. Dhara VR, Schramm PJ, Luber G. Climate change \& infectious diseases in India: implications for health care providers. Indian J Med Res. 2013 Dec;138(6):847. [PubMed] [Google Scholar]

8. Walker J. The influence of climate change on waterborne disease and Legionella: a review. Perspect Public Health. 2018 Sep;138(5):282-6. [PubMed] [Google Scholar]

9. Patz JA, Vavrus SJ, Uejio CK, McLellan SL. Climate change and waterborne disease risk in the Great Lakes Region of the US. Am J Prev Med. 2008 Nov;35(5):451-8. [PubMed] [Google Scholar]

10. Morris A, Gozlan RE, Hassani H, Andreou D, Couppié $P$, Guégan JF. Complex temporal climate signals drive the emergence of human water-borne disease. Emerg Microbes Infect. 2019 Aug;3:e56. [PubMed] [Google Scholar]

11. Sahu N, Mishra MM. Ramification of global and local climatic variability on resurgent cases of dengue in Delhi, India. Disaster Adv. 2021;14:32-40. [Google Scholar]

12. Kindig D, Stoddart G. What is population health? Am J Public Health. 2003 Mar;93(3):380-3. [PubMed] [Google Scholar]

13. Panda A, Sahu N. Trend analysis of seasonal rainfall and temperature pattern in Kalahandi, Bolangir and 
Koraput districts of Odisha, India. Atmos Sci Letter. 2019;20:1-10. [Google Scholar]

14. Panda BB, Mohanty I, Rath A, Pradhan N, Hazra RK. Perennial malaria transmission and its association with rainfall at Kalahandi district of Odisha, Eastern India: a retrospective analysis. Trop Biomed. 2019 Sep;36(3):610-9. [PubMed] [Google Scholar]

15. Albert MJ, Faruque ASG, Faruque SM, Sack RB, Mahalanabis D. Case-control study of enteropathogens associated with childhood diarrhea in Dhaka, Bangladesh. J Clin Microbiol. 1999 Nov;37(11):345864. [PubMed] [Google Scholar]

16. Kvestad I, Taneja S, Hysing M, Kumar T, Bhandari N, Strand TA. Diarrhea, stimulation and growth predict neurodevelopment in young North Indian children. PLoS One. 2015 Mar;10(3):e0121743. [PubMed] [Google Scholar]

17. Mihrete TS, Alemie GA, Teferra AS. Determinants of childhood diarrhea among under-five children in Benishangul Gumuz Regional State, North West Ethiopia. BMC Pediatr. 2014 Apr;14(1):102. [PubMed] [Google Scholar]

18. Weisz A, Meuli G, Thakwalakwa C, Trehan I, Maleta $\mathrm{K}$, Manary $\mathrm{M}$. The duration of diarrhea and fever is associated with growth faltering in rural Malawian children aged 6-18 months. Nutr J. 2011 Mar;10(1):1-4. [PubMed] [Google Scholar]

19. Mishra MM, Sahu N, Pandey BW, Singh RB. Assessing human health vulnerabilities in the blocks of Kalahandi district of Odisha, India. Disaster Adv. 2021;14(4):3240. [Google Scholar]

20. Dutta BP, Kumar N, Meshram KC, Yadav R, Sodha SV, Gupta S. Cholera outbreak associated with contaminated water sources in paddy fields, Mandla District, Madhya Pradesh, India. Indian J Public Health. 2021 Jan;65(Supplement):46-50. [PubMed] [Google Scholar] 